\title{
A RELACC̃̃O DE ESTUDANTES DO 4 ANO DO ENSINO FUNDAMENTAL COM $O$ APRENDER NA DISCIPLINA DE CIÊNCIAS EM UMA PERSPECTIVA INVESTIGATIVA: UM ESTUDO SOBRE A PROLIFERAÇÃO DO BOLOR.
}

\author{
THE RELATIONSHIP OF STUDENTS OS THE 4TH YEAR OF FUNDAMENTAL \\ EDUCATION WITH LEARNING IN THE SCIENCE DISCIPLINE FROM AN \\ INVESTIGATIVE PERSPECTIVE: A STUDY ON THE PROLIFERATION OF BOLOR.
}

Tayse Dantas dos Santos ${ }^{1}$, Veleida Anahi da Silva ${ }^{2}$

Recebido: janeiro/2020 Aprovado: agosto/2021

\begin{abstract}
Resumo: A realização de atividades investigativas contribui para que o estudante se torne responsável na construção do próprio aprendizado que, inicialmente, ocorre por meio da apresentação de um problema e pela mediação que deve ser realizada pelo professor. O objetivo deste trabalho é analisar as relações dos estudantes do 4음 ano do Ensino Fundamental de uma escola pública municipal de Aracaju - SE, com o aprender durante o ensino por investigação. O presente estudo é de cunho qualitativo e abordagem metodológica definida como pesquisa-ação. A realização da atividade investigativa, sobre a proliferação do bolor no pão, foi gravada por meio de vídeo. Entrevistas semiestruturadas foram realizadas com os estudantes após o desenvolvimento da pesquisa. Nelas, constatou-se que 61.9 \% dos estudantes desenvolveram três processos epistêmicos propostos por Charlot (2000, 2009), são eles: i) objetivação-denominação; ii) imbricação do eu; iii) distanciação-regulação, por meio dos quais foram estabelecidas cinco relações com o aprender. Essas relações ocorreram a partir dos seguintes processos que envolveram a abordagem investigativa no estudo sobre os fungos: a colocação de uma problemática, as observações realizadas, os questionamentos, as discussões desenvolvidas em sala de aula e a comunicação dos resultados obtidos.
\end{abstract}

Palavras-chave: ciências, ensino por investigação, relação com o aprender.

\begin{abstract}
The objective of this work is to analyze which and how are the relationships of students from the 4th year of elementary school in a municipal public school in Aracaju, capital of the state of Sergipe, with learning during the teaching by investigation, about the proliferation of mold. The research took place during the development and realization of the Master's dissertation of the Postgraduate Program in Teaching of Natural Sciences and Mathematics, at the Federal University of Sergipe (UFS). The conduct of the investigative activity, on the proliferation of mold in bread, was recorded through video and semi-structured interviews were conducted with students after the development of the research; the records in the format of texts and drawings produced by the students were also included in the sample. Data analysis was based on the epistemic learning processes explained by Charlot (2000, 2009), which are presented in three subsequent forms: i) objectification-denomination; ii) imbrication of the self; iii) distance-regulation. From the interviews, it was found that more than half of the students in the class developed the three epistemic processes proposed by Charlot, through which five relationships with learning were established.
\end{abstract}

Keywords: Sciences, Research teaching, Relationship with learning.

https://orcid.org/0000-0001-9443-8035 - Mestranda do Programa de Pós-Graduação em Ensino de Ciências e Matemática da Universidade Federal de Sergipe, São Cristóvão - SE, Brasil.E-mail: tayseihs@hotmail.com

2 iD https://orcid.org/0000-0002-0920-5884 - Doutora do Programa de Pós-Graduação em Educação e Pós-Graduação em Ensino de Ciências e Matemática da Universidade Federal de Sergipe, professora do Departamento de Educação, Pesquisadora e Coordenadora do Grupo de Estudos e Pesquisa Educação e Contemporaneidade/EDUCON/CNPq, São Cristóvão - SE, Brasil. Av. Marechal Rondon, s/n - Jardim Rosa Elze, São Cristóvão - SE, 49100-000, Brasil.E-mail: vcharlot@terra.com 


\section{Introdução}

O ensino por investigação constitui-se uma abordagem na qual o aprendizado ocorre por meio da colocação de um problema, do levantamento e teste de hipóteses, observações, análise e comunicação dos resultados obtidos. Dentro desse contexto, Zômpero e Laburú (2011) afirmam que um aspecto relevante a ser considerado é a necessidade de que as atividades investigativas proporcionem aos estudantes novas informações e que os resultados obtidos sejam comunicados de forma oral ou escrita. Sendo assim, é importante salientar que a realização de atividades experimentais não é condição essencial no desenvolvimento de práticas investigativas. De acordo com Sasseron (2015), o ensino por investigação consiste em uma abordagem didática vinculada a qualquer recurso de ensino que promova o processo de investigação realizado pelos estudantes com a mediação do professor.

Nesse sentido, o ensino de ciências, especificamente, por investigação contribui para que os estudantes construam o pensamento científico de maneira ativa por meio da busca pela resolução de problemas. Rodrigues e Teixeira (2018) defendem que o envolvimento dos estudantes é fundamental em atividades relacionadas ao aprender ciências que propiciam situações de diálogo com os conceitos científicos.

A partir da leitura das obras de Charlot (2000, 2005, 2009, 2013), surgiu o interesse em analisar quais relações os estudantes do $4 \stackrel{0}{\circ}$ ano do Ensino Fundamental estabelecem com a proposta de uma abordagem investigativa.

Charlot (2000) argumenta que estudar a relação com o saber é estudar o próprio sujeito confrontado com a necessidade de aprender. Nesse sentido, toda relação com o saber implica uma relação do sujeito consigo mesmo, com o outro e com o mundo. Dentro dessa perspectiva, o autor apresenta três dimensões da relação com o saber: a epistêmica, a social e a de identidade. No entanto, devido à amplitude dessas três dimensões, serão enfatizados apenas os processos epistêmicos com o saber, quais sejam: objetivação-denominação, em que aprender está na apropriação de um conteúdo intelectual que pode ser expresso por meio de conceitos, fatos e outras características; imbricação do eu, em que aprender está no domínio dos processos que envolvem a realização de uma atividade; distanciação-regulação, que está nas situações relacionais vivenciadas, na reflexão e sentimentos que o sujeito desenvolve consigo e com os outros (CHARLOT, 2000).

O interesse, em particular, por esta abordagem de ensino surgiu da primeira autora durante a graduação em licenciatura plena em Pedagogia na disciplina de "Educação Ambiental". As aulas apresentavam sugestões para a prática pedagógica por meio da realização de experimentos ou demonstrações científicas, nas quais um problema devia ser solucionado pelos estudantes, podendo ser realizado em sala de aula com materiais de fácil acesso, se adequando a falta de estrutura física e recursos didáticos que algumas escolas podem apresentar.

Diante disso, o presente estudo consistiu na realização de uma atividade investigativa, sobre a proliferação do bolor no pão, na disciplina de ciências em uma turma do 40 ano do Ensino Fundamental de uma escola pública municipal de Aracaju-SE. Dessa forma, buscou-se responder a seguinte questão: Quais as relações dos estudantes com o aprender durante a realização de 
uma atividade investigativa proposta, sobre o conteúdo programático "fungos"? O objetivo deste trabalho é analisar a relação dos estudantes com o aprender durante o ensino por investigação.

\section{Dimensões da relação com o saber: identitária, social e epistêmica.}

A relação com o saber apareceu, pela primeira vez, entre as décadas de 1960 e 1970 do século XX. No início, o enfoque era psicanalítico e posteriormente passou a ser sociológico. $\mathrm{Na}$ década de 1990, foi transposta para área da didática. Bernard Charlot realiza investigações sobre as relações que o sujeito estabelece com os saberes escolares e os fatores que podem contribuir para o sucesso e o insucesso escolar. A abordagem charlotiana sobre o sujeito, a escola e a sociedade é diferente da visão reprodutivista (CHARLOT, 2000).

Nascer e aprender é participar de um conjunto de relações que apresentam sentidos e que podem determinar quem sou eu, quem é o mundo e quem são os outros. Diante dessa perspectiva, são apresentadas três dimensões da relação com o saber, são elas: identitária, social e epistêmica (CHARLOT, 2000).

Toda relação com o saber apresenta uma relação de identidade. Ao aprender, o sujeito descobre um sentido para sua história, suas expectativas, experiências, a imagem que tem de si e a que deseja transmitir ao outro. Sendo assim, ocorre o envolvimento consigo próprio por meio do aprender, ou seja, sempre está em jogo a construção de si mesmo e seu eco reflexivo (CHARLOT, 2000).

Há também uma outra dimensão: a social. O que não significa que deva ser classificada em uma mera posição social. Esse aspecto não deve ser considerado como menos importante, pois a sociedade é composta por posições sociais, mas também constitui histórias. O "Eu", "O sujeito" é aquele que além de ocupar uma posição social ocupa uma posição escolar, que apresenta uma história formada por encontros, rupturas, aspirações: a "ter uma boa profissão", a "tornar-se alguém". Por sua vez, "O outro" pode estar representado através dos pais que atribuem responsabilidades, professores que fazem parte do processo de ensino, que ora estimulam ou desestimulam os estudantes. Não existe sujeito sem uma relação com o mundo e com o outro. Embora a ligação do sujeito com o saber seja adquirida de forma individual, ela não deixa de ser social (CHARLOT, 2000, p. 73).

Já a relação epistêmica está presente em toda situação voltada para o saber. $O$ aprender pode ser apropriado através de um objeto virtual (o "saber") que pode apresentar-se através de livros, locais (escola) e pessoas que já percorreram o caminho e adquiriram o conhecimento, como por exemplo, o professor. O aprender pode estar em "colocar coisas na cabeça", apropriar-se de saberes - objeto, conteúdos intelectuais que podem acontecer de forma precisa ou imprecisa. A forma precisa pode apresentar-se no aprendizado do teorema de Pitágoras e a imprecisa está em quando o discente atribui a escola como um lugar onde se aprende muitas coisas (CHARLOT, 2000, p. 68).

Charlot (2009) apresenta três processos epistêmicos com o saber: objetivaçãodenominação, imbricação do eu e distanciação-regulação. A objetivação-denominação consiste 
na definição de que aprender é apropriar-se de um saber enquanto objeto, sem que utilize referências a situações ou atividades que contribuíram para esse saber.

Existem formas variadas deste saber-objeto manifestar-se, são elas: no aprendizado de conceitos; a relação (entendida como ligação entre dois termos ou mais): aprendi o teorema de Pitágoras, as leis da termodinâmica entre outras situações que podem ser estabelecidas; nos fatos; na aprendizagem de teorias; nas disciplinas, ao dizer que aprendeu Matemática, Biologia e outras (CHARLOT, 2009).

Dando continuidade ao processo epistêmico voltado para objetivação-denominação, Charlot (2009) explica que quaisquer formas do saber-objeto mencionadas acima são resultados de relações. Na aprendizagem de um conceito e outros tipos de conhecimentos são estabelecidas ligações, ou seja, o saber-objeto está sempre presente por meio das relações expressadas em diferentes tipos de enunciados.

O Segundo processo que Charlot (2009) explica é a Imbricação do Eu. Nela o aprender é definido a partir do fazer, ou seja, o domínio de uma ou mais atividades. Sendo assim, Charlot (2009) explica que as relações epistêmicas referentes à Imbricação do Eu também ocorrem por meio de determinadas situações que podem remeter ao cotidiano dos sujeitos: aprender a subir em árvores, a andar de bicicleta, a arrumar a cama. Outras situações que podem ser identificadas estão em quando se aprende a ler, a escrever, a desenhar, a somar; estas são operações que implicam o corpo e o mundo constituído de materialidade.

O terceiro e último processo é a distanciação-regulação. Para Charlot (2005), essa forma epistêmica com o aprender não envolve o domínio das atividades, e sim as relações, as reflexões estabelecidas. Nesse contexto, aprender remete à capacidade de regular essas relações encontrando a distância adequada entre si e os outros, entre o sujeito e ele mesmo. A distanciação-regulação trata de sentimentos, reflexões, afetividade do sujeito, relações desenvolvidas por ele. Essas características são observadas de acordo com as situações que os envolve. O sujeito é observado como um conjunto de condutas relacionais e psíquicas implicadas em toda e quaisquer tipos de relação.

\section{Características do ensino por investigação na disciplina de ciências.}

A palavra "investigação", quando procurada no dicionário, apresenta o sinônimo de pesquisa. Durante o processo investigativo, o mais importante não é o resultado final, mas o caminho percorrido. Existem diversificadas formas pelas quais a investigação científica pode desenvolver-se, mas em todas elas são perceptíveis as seguintes características: colocação de um problema, o trabalho com os dados já existentes, o levantamento de hipóteses e suas comprovações, relações entre as informações e a construção de explicações. Essas etapas podem ocorrer em sala de aula nas mais diversificadas atividades incluindo as que envolvem leitura de texto, pois a prática investigativa não ocorre somente na realização de experimentos. Portanto, é necessário salientar que a atividade tem de fazer sentido para o aluno, de modo que saiba o motivo de estar investigando o fenômeno que lhe foi apresentado (SASSERON, 2013; AZEVEDO, 2004). 
Diante dessa perspectiva, a contextualização é um fator que também é considerado na realização dessas práticas. Nesse sentido, Carvalho (2013) explica que as práticas podem ser promovidas ao questionar os estudantes sobre em quais situações do seu cotidiano esse fenômeno se evidencia.

O ensino por investigação exige que o professor formule problemas e contribua para que os estudantes saibam resolvê-los. Ao mesmo tempo, essa abordagem demanda que o docente valorize os erros ou imprecisões expressados pelos estudantes. Ou seja, é uma nova forma de enxergar os fenômenos naturais e o modo como estamos ligados e submetidos a eles (SASSERON, 2015).

Nessa direção, Zanon e Freitas (2007) explicam que o professor deve agir como mediador e observar constantemente o comportamento dos estudantes e, quando necessário, salientar aspectos relevantes que não foram observados para o encaminhamento do problema colocado, bem como elaborar, juntamente com os estudantes, um texto coletivo que seja resultado de negociação da comunidade da sala de aula sobre os conceitos estudados.

No que tange ao desenvolvimento do ensino por investigação, existem diferentes abordagens apresentadas na visão de alguns autores, são elas: Gil Perez e Valdés Castro (1996) explicam que as orientações investigativas devem ter como características situações problemáticas abertas em um nível de dificuldade adequada para os estudantes, o levantamento de hipóteses como atividade imprescindível durante o desenvolvimento da investigação científica e a interação entre os estudantes para discussão dos resultados obtidos; Borges (2002), por sua vez, afirma que os estudantes devem resolver o problema testando suas próprias hipóteses sem a imposição de um roteiro ou por instruções apresentadas verbalmente pelo docente e, ao ser confrontado por determinada situação, seja solicitado mais que a utilização de fórmulas ou um momento semelhante que conseguiu resolver; Azevedo (2004) discorre que uma atividade é considerada investigativa quando não limita o estudante apenas a realização de observações ou manipulação de objetos, mas que apresente características de um trabalho científico - reflexão, discussão, explicação, relato dos dados obtidos.

Desse modo, ao analisar as proposições dos autores, é perceptível a existência de pontos em comum: para uma atividade de cunho investigativo é necessário a formulação de uma problemática, o levantamento de hipóteses e a comunicação dos dados ou resultados obtidos (ZÔMPERO; LABURÚ, 2011).

Dentro desse contexto, Raboni e Carvalho (2013) salientam a existência de dimensões a serem atendidas para que uma proposta de ensino apresente consistência interna e coerência com as principais linhas de pesquisa relacionadas a educação e ensino de ciências que, nesse caso, se referem as ações propostas em uma Sequência de Ensino Investigativa (SEI). Assim, os autores mencionam somente a dimensão cognitiva, que apresenta perspectivas sobre como ocorre o desenvolvimento da aprendizagem.

Diante dessa perspectiva, Carvalho (2013) afirma que ao final de uma SEI, é importante que a avaliação seja formativa e não somativa, sendo um instrumento para que estudantes e professor possam conferir se a aprendizagem está acontecendo ou não. A elaboração de uma proposta de ensino investigativa deve estar voltada tanto para o aprendizado de conceitos, quanto no desenvolvimento de práticas e valores próprios da cultura científica. Nesse sentido, a avaliação desses conceitos é a mais executada e os professores não sentem dificuldades em 
elaborar instrumentos para realizá-la. A mais tradicional é a aplicação de um questionário após o término da SEI.

Para Carvalho (2013), a proposta da avaliação cujo foco está na aprendizagem de conceitos, deve ser construída por meio de questionamentos, na organização de um painel ou em cruzadinhas. Por meio da realização de algumas dessas atividades, a avaliação dos conteúdos processuais e atitudinais também será realizada. Os conteúdos processuais e atitudinais não são avaliados com frequência na escola, mas nas práticas investigativas essas avaliações são relevantes. Sendo assim, são apresentados exemplos comportamentais que podem indicar a aprendizagem de tais conteúdos. As características que podem indicar uma aprendizagem processual podem ser demonstradas durante a resolução do problema. Dentro desse contexto, é necessário considerar a importância de observar se os estudantes estão interagindo entre si em busca da resolução da problemática, se há discussão com o objetivo de procurar ideias para levantar e testar as hipóteses.

Já a aprendizagem atitudinal pode apresentar-se nas discussões realizadas em sala de aula quando o aluno aguarda a sua vez para falar ou presta atenção e leva em consideração a fala do colega. Essa aprendizagem também pode ser identificada por meio do trabalho escrito no momento em que usam verbos de ação no plural expressando respeito pela atividade realizada em grupo. Acrescentam ainda, características que podem indicar comportamentos ao domínio procedimental: aquelas em que os estudantes descrevem o que observaram, relacionam causa e efeito, apresentam explicações sobre o fenômeno observado (CARVALHO, 2013).

\section{Metodologia}

O presente estudo é de cunho qualitativo e abordagem metodológica definida como pesquisa-ação. Minayo (2001) explica que a pesquisa qualitativa trabalha com um universo de significados, crenças, valores, atitudes. "os métodos qualitativos consideram a comunicação do pesquisador em campo como parte explícita da produção de conhecimento, em vez de simplesmente encará-la como uma variável a interferir no processo" (FLICK, 2009, p. 25).

Sobre pesquisa-ação, Pereira (2011) explica, com base nas considerações de Lewin (1965) - pioneiro desse tipo de pesquisa, que o método consiste em análise, evidência e conceitualização sobre problemas. A partir disso, ocorre o planejamento e a execução de ações, que resultam em mais evidências e avaliações; construindo, assim, um processo cíclico dessas atividades.

Sendo assim, a abordagem metodológica de pesquisa-ação que integrou o presente estudo, foi iniciado durante a graduação em licenciatura plena em Pedagogia com a realização de duas pesquisas na perspectiva do Ensino por Investigação com estudantes do ensino fundamental. As experiências adquiridas, por meio destas práticas, contribuíram para elaboração da atividade investigativa sobre o conteúdo programático "fungos" aplicada na presente pesquisa. Dessa forma, essas etapas caracterizam o processo cíclico pertencente a pesquisa-ação. 
Nesta direção, ocorreram observações das aulas de ciências de uma turma do 40 ano do Ensino Fundamental, visando à identificação de problemas para a posterior realização de intervenções praticadas pelas autoras nessa pesquisa. Logo, as ações interventivas foram originadas a partir do problema identificado e da execução de planejamentos anteriores, que permitiram o aperfeiçoamento das práticas investigativas promovidas em sala de aula. Assim, a pesquisa-ação reafirma sua natureza processual cíclica de planejar, agir, observar e refletir.

Dentro desse contexto, foram identificados a falta de incentivo à elaboração de textos. Assim, buscou-se fomentar nas crianças o desenvolvimento da escrita e, por conseguinte, responder à questão que norteia esta pesquisa: Quais as relações dos estudantes com o aprender durante a realização de uma atividade investigativa proposta, sobre o conteúdo programático "fungos"?

Porém, é importante salientar que, no presente estudo, o enfoque não está na análise da própria prática docente, mas em verificar quais as relações com o aprender a partir da reflexão sobre as intervenções realizadas durante a atividade investigativa sobre a proliferação do bolor.

A seleção da escola, campo da pesquisa, aconteceu em função da intervenção resultante do projeto pedagógico "A água e suas transformações físicas no 3o ano do ensino fundamental" ocorrida no ano de 2015.

O conteúdo programático escolhido para realização da atividade investigativa surgiu do interesse em proporcionar aos estudantes um conhecimento consistente sobre os ambientes propícios à proliferação do bolor. A elaboração da aula ocorreu com base nas ideias que Astolfi, Peterfalvi e Vérin (ASTOLFI; PETERFALVI; VÉRIN, 1998) desenvolvem em seu livro Como as crianças aprendem as ciências. $\mathrm{O} 4 \mathrm{O}$ ano do Ensino Fundamental foi selecionado para $\mathrm{O}$ desenvolvimento desta atividade investigativa, tendo em vista ser a etapa da Educação Básica em que os estudantes iniciam o estudo sobre o referido assunto, como proposto pela Base Nacional Comum Curricular (BRASIL, 2017).

A turma de 4ำ ano do Ensino Fundamental, lócus desta pesquisa, era constituída por 26 estudantes, com idades entre 9 e 11 anos. Segundo a professora regente, não há na turma crianças com dificuldades de aprendizagem comprovadas por laudo médico. Após aprovação do projeto pelo Comitê de Ética, de número 3.246.299, houve 21 autorizações dos responsáveis legais pelos estudantes por meio da assinatura do Termo de Consentimento Livre e Esclarecido - TCLE. Os estudantes participaram voluntariamente da pesquisa, o que foi atestado por meio da assinatura do Termo de Assentimento Livre e Esclarecido - TALE.

A coleta de dados aconteceu em dois momentos. No período de 13 a 27 de março de 2019, ocorreram as observações das aulas de ciências da turma lócus da investigação; e de 22 de abril a 13 de maio de 2019, aconteceu a aplicação da aula sobre a proliferação do bolor esse momento foi gravado em vídeo, juntamente com a realização das entrevistas, que foram gravadas em áudio e, posteriormente, transcritas para organização dos dados coletados. Nesse sentido, é importante destacar que tanto no TCLE quanto no TALE foram informados que a gravação de vídeos e áudios não seriam divulgados em hipótese alguma, bem como o sigilo das identidades dos participantes, sendo utilizados códigos ou números. 
Também integraram a coleta de dados os registros em formato de textos produzidos pelas crianças que, são uma ferramenta importante, pois, além de incitar a escrita dos estudantes, possibilitam a observação, de forma concreta, de como está ocorrendo a compreensão dos conteúdos abordados em sala.

Neste estudo, a atividade investigativa realizada, os textos elaborados pelos estudantes e as entrevistas foram analisados de acordo com os processos epistêmicos com o aprender apregoados por Charlot (1996, 2000, 2009).

Foi adotado, para análise dos dados coletados nas entrevistas, o método criado por Charlot (1996). Neste método analítico, a caracterização inicial de uma situação ocorre a partir de uma pluralidade de elementos heterogêneos: sexo, parentes, imagem de si mesmo, identidade pessoal e social, expectativas, entre outros. Cada um destes elementos tem de ter sentido para o indivíduo e um pode estar ligado ao outro. Ao organizar a ligação destes elementos, o pesquisador pode ter uma "constelação", sendo que o peso de cada elemento e a configuração da constelação podem mudar durante o desenvolvimento do processo, denominado como a própria dinâmica em que consequentemente ocorrem alterações de uma constelação de elementos (CHARLOT, 1996). Segundo Charlot, para argumentar:

De fato, o objetivo da análise, não esqueçamos, não é caracterizar esta ou aquela população de alunos em relação à frequência dos temas lembrados, mas identificar processos a partir de constelações de elementos que aparecem regularmente associados (1996, p. 52).

Sendo assim, as constelações são formadas por elementos agrupados para identificação de processos que estão associados. Essas constelações podem ser denominadas como categorias. Dentro dessa perspectiva, Charlot (1996) explica que as categorias, às vezes, podem ser divididas em subcategorias, e eventualmente reagrupadas. Desta feita, houve a organização das constelações de acordo com o olhar epistêmico da Relação com Saber de Bernard Charlot $(2000,2005,2009,2013)$.

Esclarecido isso, as falas das crianças que realizaram as entrevistas foram transcritas e analisadas a partir de fragmentos, pois, de acordo com Laville e Dione (1999), o recorte desses conteúdos possibilita que o pesquisador os organize em categorias em função de sua significação.

É importante salientar que as análises dos dados foram trianguladas, tendo em vista que, como argumenta Triviños (1987), a triangulação visa alcançar a máxima amplitude na descrição, explicação e compreensão do objeto de estudo.

\section{Resultados e discussões}

A partir do estudo dos processos epistêmicos apresentados por Charlot (2000, 2005, 2009, 2013), buscou-se identificar quais as relações dos estudantes do 4 o ano do Ensino Fundamental de uma escola pública municipal de Aracaju-SE com o aprender durante a realização da atividade, sobre a proliferação do bolor no pão, mediante a gravação em vídeo, registros de textos produzidos pelas crianças, bem como pela realização de entrevistas. 
Charlot (2000) explica que os estudos sobre o aprender não se restringem somente à aquisição de um conteúdo intelectual, mas a todas as relações estabelecidas pelo sujeito ao adquirir este conteúdo, pois existem diversas formas de aprender: adquirir um saber, dominar uma atividade ou objeto, adentrar em formas relacionais.

Ao explorar a relação com o saber, Carvalho (2017) esclarece que Charlot estende essa relação com o aprender. Aprender, desse prisma, vai além de uma relação com o sentido de adquirir um aprendizado de conteúdo intelectual, alcança as relações do sujeito com o mundo, com ele mesmo e com os outros.

O critério estabelecido para análise durante o desenvolvimento da atividade investigativa, registros de textos e desenhos produzidos pelas crianças, bem como a realização das entrevistas, foram os três processos epistêmicos com o aprender apregoados por Charlot (2000). Sendo assim, primeiramente, serão apresentadas as análises acerca da atividade investigativa desenvolvida.

Vale salientar que durante a realização da atividade, as crianças foram parte fundamental na construção do conhecimento tanto por meio das ações realizadas durante as práticas investigativas, quanto pelo comportamento na busca por respostas diante dos problemas propostos. A seguir, são apresentadas as análises da aula sobre a proliferação do bolor no pão.

\subsection{Realização da atividade investigativa e a apropriação do conteúdo intelectual}

Inicialmente, foram fatiados seis pães, três dos quais foram umedecidos com água e os outros não. Cada fatia de pão foi embalada separadamente em um saco plástico e devidamente lacrado. Após os pães embalados, um pão umedecido e outro seco foram depositados dentro da geladeira na cozinha da escola, um outro par foi colocado dentro de uma caixa e um último par foi posicionado em cima da caixa. Foram entregues fichas para os estudantes realizarem anotações diárias sobre as observações. Dentro deste contexto, “[...] Aprender, é exercer uma atividade em situação: em um local, em um momento da sua história e em condições de tempo diversas, com a ajuda de pessoas que ajudam a aprender. [...]" (CHARLOT, 2013, p. 67).

Assim que os pães foram devidamente alocados, os estudantes foram inquiridos sobre o que achavam que iria acontecer depois de quatro dias. Foi possível observar as concepções espontâneas dos discentes sobre os fatores que iriam contribuir para proliferação do mofo no pão, dentre eles foram apontados a umidade e o calor. Entretanto, existiram dúvidas sobre o pão umedecido guardado na geladeira e o que não foi umedecido. Neste sentido, "O problema e os conhecimentos prévios - espontâneos ou já adquiridos - devem dar condições para que os alunos construam hipóteses [...]." (CARVALHO 2013, p. 07).

Após quatro dias de observações, foi perguntado às crianças em quais situações houve o surgimento do bolor. A falta de luminosidade, como um dos elementos que colabora para proliferação do bolor, e a baixa temperatura da geladeira, que contribui para o retardamento deste processo, foram mencionados. Estas características não foram citadas pelos estudantes no início das investigações, ou seja, o desenvolvimento da prática investigativa ao longo da semana possibilitou tanto o levantamento quanto a descoberta de novas variáveis. Durante esse 
período, ocorreu, de forma gradativa, apropriação do conteúdo intelectual sobre os conceitos relacionados à proliferação do bolor, isto é, o processo epistêmico da objetivação-denominação.

Este processo epistêmico com o aprender ocorreu também no momento em que os estudantes chegaram à conclusão de que ambientes úmidos, escuros e quentes contribuem para o surgimento do mofo. Charlot (2009) argumenta que na objetivação-denominação os estudantes podem enunciar conceitos, fatos, teorias, aprendizados de disciplinas escolares sem referir-se a situações ou às atividades através das quais este objeto foi construído.

Charlot (1996) afirma também que o processo epistêmico de objetivação-denominação possibilita a denominação de um saber que the dá estatuto de objeto. Neste sentido, a linguagem tem papel fundamental, pois permite a existência do saber enquanto objeto. $O$ autor ressalta ainda que a linguagem não constitui o saber, pois ele se constrói através de uma atividade específica, de uma atividade intelectual sem se referir à atividade que o construiu.

Sendo assim, a partir das análises realizadas sobre o desenvolvimento da atividade, na perspectiva do ensino por investigação, verificamos que o processo epistêmico com o aprender na forma da objetivação-denominação ocorreu por meio das observações que aconteceram durante os quatro dias sobre a proliferação do bolor nos pães e das discussões realizadas em sala de aula, sistematizando as informações sobre as circunstâncias que contribuíram para esta situação.

Este processo também foi identificado nos registros em forma de textos produzidos pelas crianças que será analisado na subseção seguinte.

\subsection{Os registros de textos produzidos pelas crianças e a identificação de dois processos epistêmicos}

Os registros em textos, além de demonstrarem, de forma concreta, a apropriação do conteúdo abordado na atividade investigativa, possibilitaram a verificação de outro processo epistêmico: a imbricação do eu.

Após o período de quatro dias de observações sobre a proliferação do bolor no pão, foram realizadas discussões sobre os fatores que contribuíram para o processo. Organizados em quatro grupos, sendo três compostos por quatro integrantes e um grupo com cinco, foram solicitados que os estudantes produzissem um texto comunicando os resultados obtidos, de acordo com as discussões realizadas em sala de aula e com as anotações feitas em suas fichas durante os dias em que observaram a proliferação do bolor.

No primeiro momento, as crianças sentiram dificuldades na produção dos textos, então, foram orientados a contarem verbalmente como a atividade aconteceu. Ao final, os estudantes foram instruídos a transpor tudo que haviam falado para o papel. Esse segundo momento possibilitou uma análise detalhada dos processos epistêmicos com o aprender, sobre a objetivação-denominação e a imbricação do eu.

A seguir, na Figura 1, está o registro em texto produzido pelo primeiro grupo e a transcrição desse conteúdo pode ser observada no Quadro 1. É importante salientar que houve a transcrição de todos os textos e os erros ortográficos foram mantidos. 


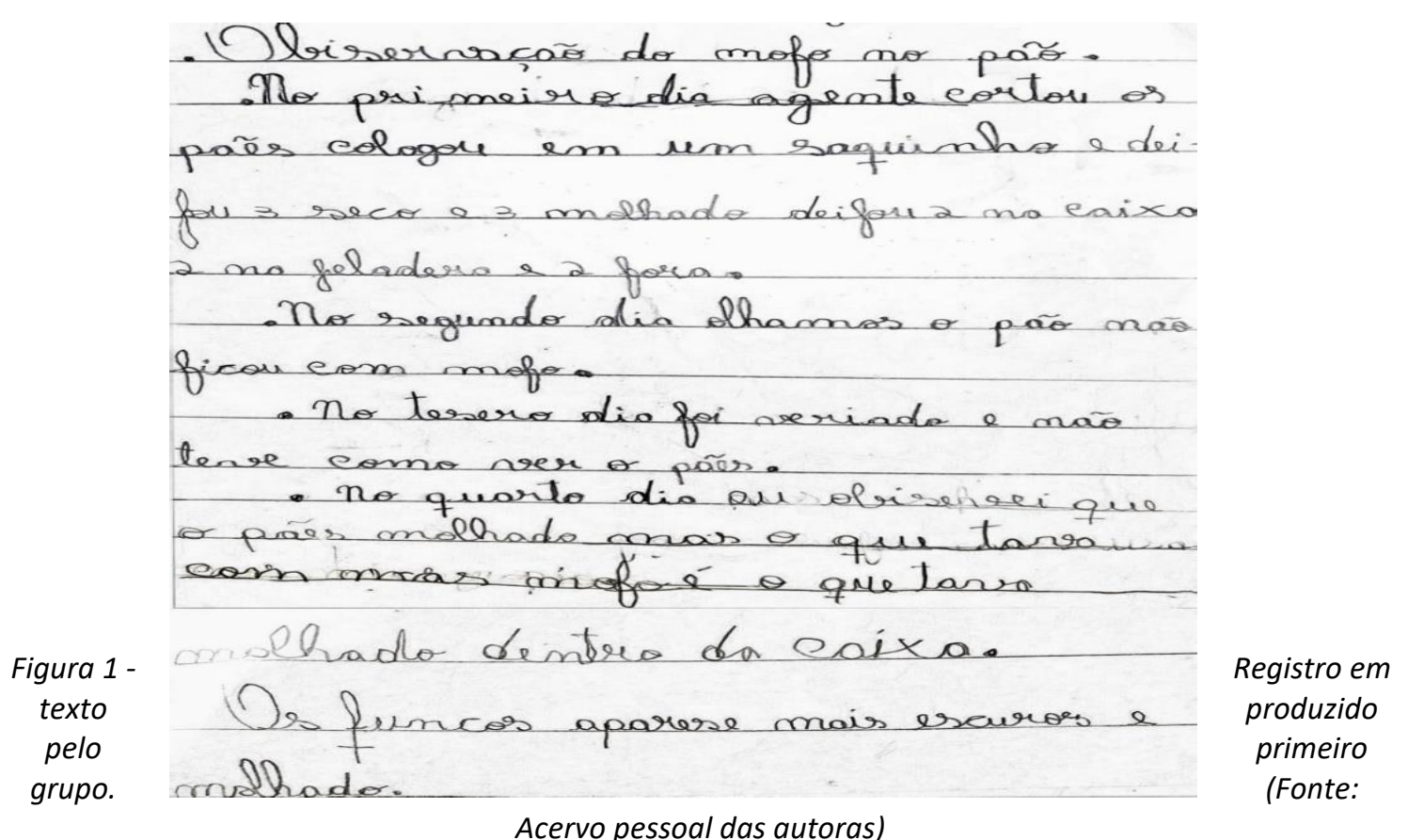

Quadro 1- Transcrição do registro em texto produzido pelo primeiro grupo

Observação do mofo no pão

No primeiro dia agente cortou os pães colocou em um saquinho e deifou 3 seco e 3 molhado deifou 2 na caixa e na geladeira e 2 fora.

No segundo dia olhamos o pão não ficou com mofo.

No tesero dia foi veriado e não teve como ver o pães.

No quarto dia eu observei que o pães molhado mas o que tava com mas mofo é o que tava molhado dentro da caixa.

Os fungos aparese mais escuros e molhados.

O processo epistêmico da imbricação do eu foi identificado em todos os textos produzidos pelas crianças, no momento em que descreveram os procedimentos realizados com os pães e os ambientes em que foram colocados; e a objetivação-denominação foi demonstrada quando os estudantes relataram os fatos que contribuíram para proliferação do bolor. Porém, em alguns registros esses processos estão presentes de forma mais ou menos detalhada. No registro do primeiro grupo, na Figura 1, foram dadas explicações mais específicas tanto em relação as etapas desenvolvidas para realização da atividade investigativa, quanto na identificação do ambiente em que houve maior proliferação do bolor no pão. Diante do exposto, o texto produzido pelo quarto grupo apresentou as mesmas características aos da primeira equipe.

Partindo desse contexto, no registro do segundo grupo, foi identificado o processo epistêmico da objetivação-denominação no momento em que os estudantes relataram sobre o 
ambiente propício para o surgimento do mofo no pão, especificando também o aspecto dos que foram colocados em cima da caixa. No que tange ao processo epistêmico da imbricação do eu, faltou uma descrição detalhada sobre os processos adotados para realização da atividade investigativa, bem como os diferentes ambientes em que os pães foram armazenados. $O$ grupo destacou apenas um local de armazenamento, a geladeira. O conteúdo desse texto está apresentado na Figura 2 e sua transcrição foi realizada no Quadro 2, abaixo.

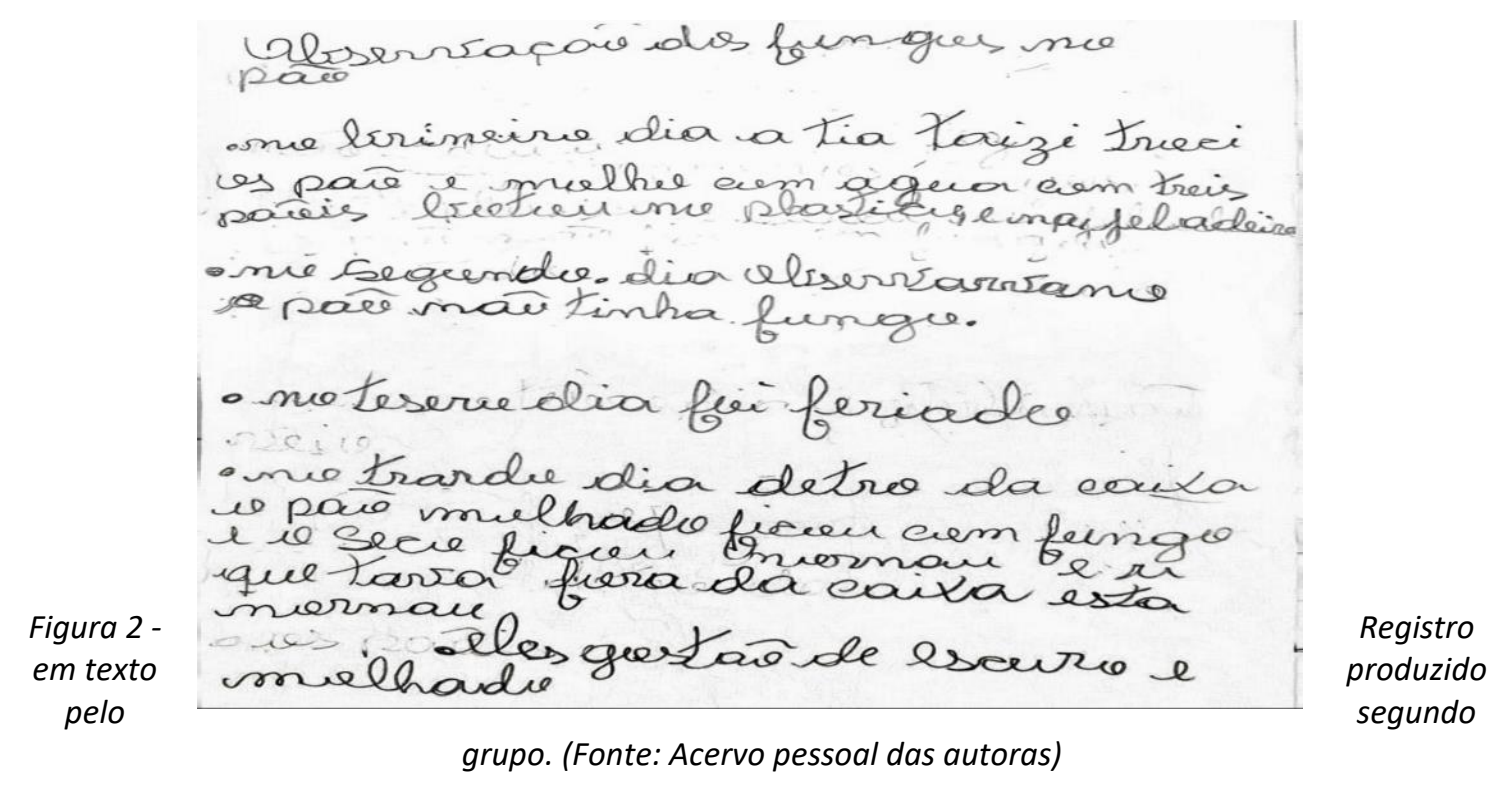

Quadro 2 - Transcrição do registro em texto produzido pelo segundo grupo

Observação dos fungus no pão
no brineiro dia a tia taizi troci os pão e molho com água com treis pãois
botou no plasticu e na jeladeira
no segundo dia observarvano o pão não tinha fungo.
No tesero dia foi feriado
no trardo dia detro da caixa o pão mulhado ficou com fungo e o seco
ficou nornau e u que tava fora da caixa esta nornau eles gostão de escuro
e molhado.

Já no texto produzido pela terceira equipe, Figura 3, não ocorreu um relato completo sobre qual ambiente de armazenamento o pão molhado estava para que houvesse a proliferação do bolor, mas em relação aos procedimentos realizados e os ambientes em que os pães foram colocados houve um maior detalhamento nas descrições, estabelecendo o processo epistêmico da imbricação do eu. A transcrição do registro de texto elaborado pelo terceiro grupo pode ser observada no Quadro 3, a seguir. 




Figura 3 - Registro em texto produzido pelo terceiro grupo. (Fonte: Acervo pessoal das autoras)

Quadro 3 - Transcrição do registro em texto produzido pelo terceiro grupo

Observação dos mofo no pão
No primeiro dia trosse o pão cortado en fatias, cortaram seis fatias e três
foram molhadas e as outras três ficaram secas e depois colocaram pacotes, 2 caixa
2 fora da caixa e 2 na geladeira.
No segundo dia olhamos os pães e não estavam com mofo.
No terseiro dia não podemos ver os pães porque não viemos.
No quarto dia nos olhamos pelo microscopio os fungos e os que estavam
com mofo foi os pães molhados e os fungos gosta de lugares escuros molhados
claro e secos.

De acordo com Carvalho et al. (2010) explicam que, quando os estudantes estão livres para escrever, podem surpreender seus professores com a criatividade. Porém, o docente não deve esperar que eles relatem detalhadamente tudo que aconteceu, pois eles se detêm nos aspectos que mais chamaram sua atenção. Dentro dessa perspectiva, Zanon e Freitas (2007) destacam a importância dos estudantes articularem a expressão oral e escrita com base nas práticas investigativas. Nesse sentido, a escrita e a leitura apresentam significados, pois são instrumentos relevantes de comunicação e registro das concepções, da questão de pesquisa 
colocada, das observações realizadas, das informações constatadas e do texto coletivo negociado. Segundo Oliveira, para argumentar:

Assim, não se poderia pensar em ensino e aprendizagem de Ciências sem pensar no ensino e aprendizagem da argumentação e da escrita. Só se aprende fazendo...dessa forma, só é possivel aprender a argumentar e escrever sobre um fenômeno se é propiciado aos alunos esse momento de se experimentar e aperfeiçoar-se nessas modalidades de linguagem tão caras para a Ciência $(2013$, p.64).

Diante disso, cabe ao ensino de ciências estimular a prática da escrita após a finalização da atividade investigativa "[...] os desenhos ou redações não devem ser feitos em casa, mas na sala, enquanto os alunos estão motivados pelo experimento recém-realizado e pela discussão e têm por isso muitas coisas para contar" (CARVALHO et al., 2010, p. 39).

Enfim, foi possível observar que as crianças desenvolveram o processo epistêmico da objetivação-denominação tanto no desenvolvimento da atividade investigativa quanto na produção de registros em textos. Posteriormente, iremos identificá-lo também nas entrevistas, bem como a imbricação do eu, que, inicialmente, apresentou-se nos registros produzidos pelas crianças. Sendo assim, verificamos outro processo epistêmico presente nas entrevistas: a distanciação-regulação. Essas análises serão apresentadas, detalhadamente, na subseção seguinte.

\subsection{Os processos epistêmicos com o aprender e as relações estabelecidas durante a realização da atividade investigativa sobre a proliferação do bolor}

A análise das entrevistas resultou na formação de oito constelações, são elas: a) aprendizagens ligadas à proliferação do mofo; b) aprendizagens ligadas as diferentes nomenclaturas atribuídas ao tipo de fungo estudado; c) aprendizagens ligadas à presença microscópica do bolor; d) aprendizagens ligadas a acontecimentos cotidianos; e) aprendizagem ligada aos malefícios causados pelo bolor; f) aprendizagens ligadas aos malefícios e benefícios dos fungos; g) os malefícios que os fungos causam à saúde; e h) os fungos que são prejudiciais e os que não causam danos à saúde.

Segundo Charlot (1996), as constelações são formadas a partir de elementos heterogêneos: imagem de si mesmo, identidade pessoal e social, competências sociais, cognitivas, de linguagem, entre outros. O critério adotado para a organização dessas constelações ocorreu de acordo com os processos epistêmicos com o aprender apresentados por Charlot $(2000,2009)$. Vale salientar que uma mesma fala pode pertencer a dois processos epistêmicos distintos.

Primeiramente, são analisadas as respostas das crianças originadas por meio da seguinte pergunta: "o que você aprendeu durante as aulas que participou?". Os resultados obtidos remeteram ao processo da objetivação-denominação; os estudantes A8 e A12, no entanto, não conseguiram desenvolver este processo epistêmico. Na sequência, são apresentadas as falas desses estudantes. 
Não sei (A8).

Não lembro de nada (A12).

Charlot (2009) explica que a forma epistêmica da objetivação-denominação com o aprender constitui enunciados e apropriações de conteúdos intelectuais. Essa enunciação pode compor o próprio termo que denomina o conteúdo, como por exemplo, aprender genética, ou então denominar conceitos que fazem parte do conteúdo intelectual.

$\mathrm{Na}$ presente pesquisa, esse processo epistêmico com o aprender ocorreu através da denominação do conteúdo intelectual e da descrição dos conceitos que fazem parte desse mesmo conteúdo, voltado para o assunto que integrou a aula.

Diante disso, o processo da objetivação-denominação originou seis constelações, a saber: a) aprendizagens ligadas à proliferação do mofo; b) aprendizagens ligadas as diferentes nomenclaturas atribuídas ao tipo de fungo estudado; c) aprendizagens ligadas à presença microscópica do bolor; d) aprendizagens ligadas a acontecimentos cotidianos; e) aprendizagem ligada aos malefícios causados pelo bolor; f) aprendizagens ligadas aos malefícios e benefícios dos fungos.

Essas constelações foram analisadas, primeiramente, de acordo com as explicações contidas em livros didáticos, na perspectiva de confrontar as afirmações das crianças com as explicações científicas. Já as relações que foram estabelecidas serão explicadas posteriormente. Assim sendo, a seguir cada constelação mencionada anteriormente será analisada.

Na sequência, no Quadro 4, são apresentados trechos das entrevistas relacionados a primeira constelação: aprendizagens ligadas à proliferação do mofo.

Quadro 4 - Respostas dos estudantes relacionadas ao processo epistêmico da objetivação-denominação que originaram a constelação: Aprendizagens ligadas à proliferação do mofo

\begin{tabular}{|c|l|}
\hline \multicolumn{2}{|c|}{ Aprendizagens ligadas à proliferação do mofo } \\
\hline Locutor & \multicolumn{1}{|c|}{ Falas transcritas } \\
\hline A1 & $\begin{array}{l}\text { Aprendi a não deixar muita coisa molhada dentro da geladeira ou fora } \\
{[\ldots]}\end{array}$ \\
\hline A3 & Que os fungos gostam de lugares molhados e escuros \\
\hline A10 & $\begin{array}{l}\text { Eu aprendi que os fungos gostam de lugares úmidos e lugares escuros. } \\
{[\ldots]}\end{array}$ \\
\hline A11 & $\begin{array}{l}\text { Que os fungos têm várias maneiras de falar: ele é mofo, bolor [...]. } \\
\text { Descobri que os fungos gostam de lugares úmidos e quentes }\end{array}$ \\
\hline
\end{tabular}

Fonte: Elaborado pelas autoras.

Nota-se que A1, A3, A10 e A11 desenvolveram o processo epistêmico da objetivaçãodenominação ao descrever conceitos do conteúdo intelectual relacionados às características propícias à proliferação do mofo. Isso vai ao encontro das explicações de Barros e Paulino (2015) quando afirmam que, em geral, os fungos se desenvolvem em lugares úmidos e com pouca 
luminosidade. Diante do exposto, é importante salientar que os estudantes A5, A15, A18 e A19 apresentaram as mesmas ideias de A1 e A3.

A seguir, no Quadro 5, trechos das entrevistas que tratam da segunda constelação: aprendizagens ligadas as diferentes nomenclaturas atribuídas ao tipo de fungo estudado.

Quadro 5 - Respostas dos estudantes relacionadas ao processo epistêmico da objetivação-denominação que resultaram na constelação: aprendizagens ligadas as diferentes nomenclaturas atribuídas ao tipo de fungo estudado

\begin{tabular}{|c|l|}
\hline \multicolumn{2}{|c|}{ Aprendizagens ligadas as diferentes nomenclaturas atribuídas ao tipo de fungo } \\
estudado
\end{tabular}

Fonte: Elaborado pelas autoras.

É importante ressaltar que a fala de A11 pertence tanto a constelação mencionada no Quadro 4, quanto a constelação do Quadro 5, pois, cita as diferentes nomenclaturas que um mesmo tipo de fungo pode receber. Nessa direção, o livro didático explica que um fungo pode ser denominado de bolor ou mofo (GOWDAK; MARTINS, 2009).

Os fungos que não são visualizados sem a utilização de um microscópio também foi assunto nas entrevistas com os discentes e constituiu a terceira constelação: aprendizagens ligadas à presença microscópica do bolor. A seguir, no Quadro 6, alguns fragmentos das entrevistas evidenciam esse aspecto.

Quadro 6 - Respostas dos estudantes relacionadas ao processo epistêmico da objetivação-denominação que determinaram a formação da constelação: aprendizagens ligadas à presença microscópica do bolor

\begin{tabular}{|c|l|}
\hline \multicolumn{2}{|c|}{ Aprendizagens ligadas à presença microscópica do bolor } \\
\hline Locutor & \multicolumn{1}{|c|}{ Falas transcritas } \\
\hline A16 & $\begin{array}{l}\text { Que se a pessoa quiser comer alguma coisa e ela tiver com mofo, bolor } \\
\text { aím uma parte que tá normal e a outra tá verde. Se ela tirar a parte } \\
\text { verde, ainda vai ter fungo na outra parte porque eles são } \\
\text { microscópicos. }\end{array}$ \\
\hline A21 & $\begin{array}{l}\text { Que quando a gente pega um pão com mofo, não pode comer porque } \\
\text { está infectado em todo o pão. }\end{array}$ \\
\hline
\end{tabular}

Fonte: Elaborado pelas autoras.

Os conceitos explicados por A16 e A21 descrevem a presença do mofo de forma microscópica nos alimentos. Na mesma perspectiva, Silva (2012) discorre sobre o esquema do 
desenvolvimento dos fundos nos alimentos. A parte na qual o bolor fica visível a olho nu é como se fosse apenas a ponta do iceberg, pois estes fungos são compostos por três partes: filamentos de raiz, um caule e esporos. Os filamentos de raiz penetram no alimento; o caule fica sobre a superfície dos alimentos; e os esporos são formados no final do caule. Quando estes ficam visíveis, os filamentos da raiz já estão presentes em todo o alimento, e, por esta razão, o alimento não deve ser ingerido.

Dando continuidade ao processo epistêmico da objetivação-denominação, foram identificadas nas falas de A4 e A13 a denominação do conteúdo expressando descobertas realizadas após a atividade investigativa, ajudando-os no reconhecimento de situações cotidianas. Esses dados contribuíram para o surgimento de uma quarta constelação, ei-la: aprendizagens ligadas a acontecimentos cotidianos. As falas desses estudantes estão apresentadas no Quadro 7, a seguir.

Quadro 7 - Respostas dos estudantes relacionadas ao processo epistêmico da objetivação-denominação que originaram a constelação: aprendizagens ligadas a acontecimentos cotidianos

\begin{tabular}{|c|c|}
\hline \multicolumn{2}{|c|}{ Aprendizagens ligadas a acontecimentos cotidianos } \\
\hline Locutor & \multicolumn{1}{|c|}{ Falas transcritas } \\
\hline A4 & $\begin{array}{l}\text { Sobre as manchas na camisa. Porque eu deixei muito tempo no } \\
\text { guarda roupa aí criou aquelas bolinhas. Descobri que aquilo é mofo. }\end{array}$ \\
\hline A13 & As manchas verdes que já vi em paredes e nos pães eram fungos. \\
\hline
\end{tabular}

Fonte: Elaborado pelas autoras.

A descoberta de A4 está em concomitância com as explicações científicas. Gowdak e Martins (2009) afirmam em seu livro didático que depois de algum tempo, podem aparecer manchas esbranquiçadas nas roupas, principalmente se o armário não tiver ventilação. Motta (2016), por seu turno, confirma a explicação de A13. Os fatores que podem contribuir para identificação de um alimento estragado são aparência, cheiro e sabor alterados, e essas características são causadas pela ação dos fungos.

Na sequência, no Quadro 8, é apresentada a fala de A17 que deu origem a quinta constelação: aprendizagem ligada aos malefícios causados pelo bolor.

Quadro 8 - Resposta do estudante relacionada ao processo epistêmico da objetivação-denominação que formou a constelação: Aprendizagem ligada aos malefícios causados pelo bolor

\begin{tabular}{|c|l|}
\hline \multicolumn{2}{|c|}{ Aprendizagem ligada aos malefícios causados pelo bolor } \\
\hline Locutor & \multicolumn{1}{|c|}{ Fala transcrita } \\
\hline A17 & $\begin{array}{l}\text { Sobre o pão mofado, aprendi que quando a gente vê um pão que } \\
\text { tá verde não pode comer porque pode dar mal estar. }\end{array}$ \\
\hline
\end{tabular}

Fonte: Elaborado pelas autoras. 
A17 denominou o conteúdo intelectual e explicou os prejuízos causados à saúde caso haja o consumo de alimentos contendo bolor. Confirmando as explicações do estudante, Motta (2016) afirma que o consumo de alimentos estragados pode causar intoxicação alimentar e outras doenças.

Por fim, percebemos que as falas de $A 2, A 6$ e $A 20$ ocorreu um equilíbrio do pensamento científico no processo epistêmico que desenvolveram com o aprender devido as explicações dadas, de forma breve, referente a descoberta de Alexander Fleming sobre um fungo do gênero Penicillium que deu origem ao antibiótico. Foi explicada a eficácia desse medicamento no combate de muitas doenças infecciosas. Estes estudantes demonstraram um equilíbrio na apropriação do conteúdo intelectual quanto aos fungos prejudiciais à saúde, bem como aos que contribuem para nosso bem-estar. Sendo assim, as falas desses discentes, que estão apresentadas no Quadro 9, formaram a sexta constelação: aprendizagens ligadas aos malefícios e benefícios dos fungos.

Quadro 9 - Respostas dos estudantes relacionadas ao processo epistêmico da objetivação-denominação que formaram a constelação: aprendizagens ligadas aos malefícios e benefícios dos fungos

\begin{tabular}{|c|l|}
\hline \multicolumn{2}{|c|}{ Aprendizagens ligadas aos malefícios e benefícios dos fungos } \\
\hline Locutor & $\begin{array}{l}\text { Que não pode deixar as coisas molhadas e que também têm fungos que } \\
\text { são bons. Aquele homem que criou o remédio com o fungo, ele deixou a } \\
\text { janela aberta e entrou muito sol em seu laboratório, onde tinha uma } \\
\text { plaquinha com monte de bactéria. Quando ele chegou tinha uma bolinha } \\
\text { ao redor das bactérias e elas estavam todas mortas. Ele ajudou a não } \\
\text { amputar braços e pernas na guerra, criando esse remédio por que a } \\
\text { bactéria morria. O antibiótico fez uma coisa do bem. Tem o fungo do bem } \\
\text { e o fungo do mal. }\end{array}$ \\
\hline A6 & $\begin{array}{l}\text { Que têm fungos que transmitem doenças e têm outros fungos que criam } \\
\text { os antibióticos. }\end{array}$ \\
\hline A20 & $\begin{array}{l}\text { Eu aprendi que têm fungos perigosos e outros não. E têm os que fazem } \\
\text { bem à saúde, aquele do antibiótico. }\end{array}$ \\
\hline
\end{tabular}

Fonte: Elaborado pelas autoras.

Nessa direção, o livro didático explica sobre o perigo que alguns tipos de fungos podem apresentar, como por exemplo, a maioria das espécies de cogumelos e outros fungos que podem ser aproveitados na produção de pães, bebidas ou medicamentos. No caso dos medicamentos, a penicilina, oriunda do bolor Penicillium notatum (CANTO, 2012).

Partindo das explicações apresentadas pelos estudantes durante a realização das entrevistas, Raboni e Carvalho (2013) afirmam que os discentes possuem um vasto reportório de palavras construídas em situações concretas da vida cotidiana. A comunicação das ideias surge em situações igualmente concretas. Assim, a articulação das palavras e a referência que fazem durante as observações realizadas em sala de aula estão presentes na base do 
conhecimento que trazem da vida cotidiana. Conhecer e explorar essa capacidade de se expressar faz parte da valorização dos conhecimentos prévios e superação dos mesmos.

Diante das falas que integraram cada constelação é necessário salientar, mais uma vez, a afirmação que Charlot (2009) realiza quanto ao saber-objeto. O saber-objeto pode manifestarse de várias formas: conceitos, fatos, teorias, disciplinas.

Após o confronto entre as afirmações dos estudantes sobre o que aprenderam durante as aulas que participaram com as explicações científicas apresentadas em livros didáticos, foi observado que o processo epistêmico da objetivação-denominação se apresentou de duas formas: conceitos e fatos.

Sendo assim, a organização das constelações permitiu a análise de quais tipos de relações os estudantes estabeleceram com o aprender durante o desenvolvimento de uma aula, na perspectiva do ensino por investigação, em um estudo sobre a proliferação do bolor, quais sejam: a relação com o aprender na descrição de conceitos de um conteúdo intelectual e a relação com o aprender a denominar um conteúdo intelectual.

A relação com o aprender na descrição de conceitos de um conteúdo intelectual foi expressa a partir das seguintes constelações: aprendizagens ligadas à proliferação do mofo; aprendizagens ligadas as diferentes nomenclaturas atribuídas ao tipo de fungo estudado; aprendizagens ligadas à presença microscópica do bolor.

A segunda relação estabelecida corresponde à relação com o aprender a denominar um conteúdo intelectual. Essa relação apresentou-se por meio das constelações "aprendizagens ligadas a acontecimentos cotidianos"; "aprendizagem ligada aos malefícios causados pelo bolor"; e "aprendizagens ligadas aos malefícios e benefícios dos fungos".

As relações estabelecidas aconteceram por meio do processo que envolve o ensino por investigação. Para entendermos esse processo, Fireman e Brito (2018) explicam que a aprendizagem de conteúdos conceituais, em uma atividade investigativa, ocorre por meio de um problema a ser resolvido. $O$ estudante pode encontrar limitações em compreender o objeto de estudo. Assim, passam a agir sobre esse objeto com o levantamento e teste de hipóteses, a observação das evidências, explicações sobre as relações causais, conclusões e justificativas dessas conclusões em uma dinâmica dialógica.

Ou seja, o exercício de pensar sobre esse agir constitui um elemento desencadeador para tomada de consciência da ação sobre o objeto que pode desenvolver o raciocínio científico e contribuir para elaboração de conceitos por meio de um processo e não de produto (FIREMAM; BRITO, 2018).

Pozo e Crespo (2009) afirmam que uma pessoa adquire um conceito quando é capaz de atribuir significado a um material ou informação que lhes são apresentados, isto é, quando há compreensão desse material; e compreender equivale a expressar algo com suas próprias palavras.

Já de acordo com Serra (2013), o ensino de ciências nas séries iniciais deve promover a compreensão e reflexão sobre o significado e a importância das ciências naturais para que os 
estudantes construam, da melhor forma, seus conceitos e aprendam de modo significativo sobre o ambiente que os rodeiam.

Outro processo epistêmico com o aprender desenvolvido por meio da aplicação da sequência de ensino investigativa também foi analisado: a imbricação do eu. Identificamos esse processo pelo seguinte questionamento, que integrou a entrevista: qual atividade você mais gostou? Por quê? Explique como aconteceu. Vale salientar que A8 e A12 não desenvolveram essa forma epistêmica com o aprender. Na sequência, são apresentadas as falas desses estudantes.

Não sei explicar. Não me lembro bem (A8).

A do pão. Mas não sei dizer (A12).

Charlot (2000) esclarece que na imbricação do eu o aprender está no domínio de uma atividade, ou seja, quando o estudante sabe desenvolvê-la ou na utilização de um objeto. Esse processo epistêmico apresentou-se por meio do domínio da atividade de investigação científica enunciado pelos estudantes sobre as ações que realizaram.

Dentro desse contexto, não houve a organização das constelações devido à ocorrência da saturação de dados. Sobre isso, Bauer e Gaskell (2003) explicam que em alguns momentos o pesquisador se dá conta de que não aparecerão novas surpresas, que possam colaborar para o desenvolvimento da pesquisa, o que é um sinal de que é tempo de parar e conferir sua compreensão sobre o que já se tem. Nesse sentido, alguns fragmentos das entrevistas são apresentados no Quadro 10 e evidenciam a saturação desses dados.

Quadro 10 - Respostas dos estudantes relacionadas ao processo epistêmico da imbricação do eu

\begin{tabular}{|c|l|}
\hline Locutor & \multicolumn{1}{|c|}{ Falas transcritas } \\
\hline A1 & $\begin{array}{l}\text { A do pão, essa da...você chamou seis pessoas pra cortar o pão e não deixar } \\
\text { muito molhado. Três pão [sic] molhados e três pão [sic] secos e cada um } \\
\text { botando no negócio. Um molhado e um seco na luz, um seco e um molhado } \\
\text { dentro da caixa e o molhado e o seco dentro da geladeira }\end{array}$ \\
\hline A2 & $\begin{array}{l}{[\ldots . .] \text { Primeiro você trouxe seis pães aí você pediu pra gente botar três com água }} \\
\text { e três sem água. Botou dois na caixa, dois fora e dois dentro da geladeira. [...] }\end{array}$ \\
\hline A3 & $\begin{array}{l}\text { A gente cortou o pão em fatias e colocou dentro do saquinho, um molhado e } \\
\text { o outro não. Depois foi guardando em lugares em que poderia ficar mofado. } \\
\text { Tipo... dentro da caixa, fora da caixa e na geladeira. [...] }\end{array}$ \\
\hline A4 & $\begin{array}{l}\text { A gente cortou o pão e molhou, um deixou seco. Colocou em lugares escuros } \\
\text { e quentes. A mesma coisa fora da caixa, molhado e seco, e na geladeira. [...] }\end{array}$ \\
\hline A5 & $\begin{array}{l}\text { Tia, a gente cortou os pães em seis partes. Molhamos três e deixamos as } \\
\text { outras secas. Depois colocamos em lugares diferentes. Uma seca e uma } \\
\text { molhada dentro da caixa, uma seca e outra molhada fora da caixa e uma seca } \\
\text { e uma molhada dentro da geladeira na cozinha daqui. }\end{array}$ \\
\hline
\end{tabular}




\begin{tabular}{|c|c|}
\hline A6 & $\begin{array}{l}\text { A gente cortou três pães, borrifou água nos três; cortou mais três pães e } \\
\text { deixou seco aí foi um molhado e um seco para geladeira, um molhado e um } \\
\text { seco na caixa, um molhado e um seco exposto na luz [...] }\end{array}$ \\
\hline A7 & $\begin{array}{l}\text { Cortamos os pães em seis pedaços. Deixamos três pedaços molhados e os } \\
\text { outros sem água. Depois colocamos um pedaço molhado e um seco dentro de } \\
\text { uma caixa. Outro molhado e outro seco fora da caixa e os outros na geladeira } \\
\text { para ver onde ia pegar mais bolor. }\end{array}$ \\
\hline A9 & $\begin{array}{l}\text { A gente cortou dois pão [sic], colocamos um molhado e um seco dentro da } \\
\text { caixa, um molhado e um seco na geladeira e um molhado e um seco fora da } \\
\text { geladeira. }\end{array}$ \\
\hline A10 & $\begin{array}{l}\text { [...] Alguns a gente molhou com água e outros a gente deixou seco. Dois } \\
\text { colocamos na geladeira. Dois colocamos dentro da caixa e dois a gente colocou } \\
\text { fora da caixa. [...] }\end{array}$ \\
\hline A11 & $\begin{array}{l}\text { Dividimos seis fatias de pães. Duas fatias, uma molhada e uma seca. Uma } \\
\text { molhada e uma seca pra geladeira, uma molhada e uma seca fora da caixa e } \\
\text { outras duas dentro da caixa. [...] }\end{array}$ \\
\hline A13 & $\begin{array}{l}\text { A gente cortou o pão, colocou no saquinho, mas antes molhamos alguns pães. } \\
\text { Colocamos dois na geladeira e os outros fora. [...] }\end{array}$ \\
\hline A14 & $\begin{array}{l}\text { Primeiro teve um sorteio pra ver quem ia cortar os pães. Depois mandou } \\
\text { molhar, botar na geladeira, mas o pão ficou dentro de uma mochila. Botou um } \\
\text { molhado e um seco em cima da caixa e outro molhado e seco dentro da caixa. } \\
{[\ldots]}\end{array}$ \\
\hline A15 & $\begin{array}{l}\text { Foram seis fatias de pães. Molhamos três e as outras não molhamos. } \\
\text { Colocamos em saquinhos e depois colocamos uma fatia seca e outra molhada } \\
\text { dentro de uma caixa. Depois uma seca e outra molhada fora da caixa e uma } \\
\text { fatia seca e outra molhada dentro da geladeira. }\end{array}$ \\
\hline A16 & $\begin{array}{l}\text { Primeiro, a senhora trouxe o pão, cortamos em forma de torrada. Deixamos } \\
\text { dois molhados na geladeira, dois em uma caixa escura e outros dois fora da } \\
\text { caixa. }\end{array}$ \\
\hline A17 & $\begin{array}{l}\text { A gente cortou seis pães. Molhamos três e deixamos os outros secos. } \\
\text { Colocamos em sacos e depois guardamos um molhado e um seco dentro da } \\
\text { caixa, um molhado e um seco fora da caixa e os outros na geladeira pra ver } \\
\text { qual ia ficar com mofo. }\end{array}$ \\
\hline A18 & $\begin{array}{l}\text { Cortamos o pão, colocamos dentro da sacola e molhamos. Colocamos dois } \\
\text { pães na geladeira, um molhado e outro seco. Outros dois na caixa, um } \\
\text { molhado e outro seco, e colocou fora da caixa um molhado e outro seco. [...] }\end{array}$ \\
\hline
\end{tabular}




\begin{tabular}{|l|l|}
\hline A19 & $\begin{array}{l}\text { Foi assim, a gente pegou os pães e cortou, colocou um molhado dentro do } \\
\text { saco e outro seco em outro saco. Colocamos dois na geladeira, dois dentro da } \\
\text { caixa e dois fora da caixa. [...] }\end{array}$ \\
\hline A20 & $\begin{array}{l}\text { Cortamos os pães em seis fatias. Depois molhamos três e deixamos as outras } \\
\text { sem molhar. Colocamos uma molhada e a outra seca dentro de uma caixa } \\
\text { bonita, outra molhada e outra seca fora da caixa e outra molhada e outra seca } \\
\text { dentro da geladeira. }\end{array}$ \\
\hline A21 & $\begin{array}{l}\text { A gente cortou a fatia de pão e uma ficava molhada e outra seca. Colocava no } \\
\text { pacote. Colocamos dois dentro da caixa, um molhado e um seco, fora da caixa, } \\
\text { um molhado e um seco, e dento da geladeira, um molhado e um seco. }\end{array}$ \\
\hline
\end{tabular}

Fonte: Elaborado pelas autoras.

Diante do exposto, os fragmentos das falas evidenciam a ação realizada pelos sujeitos durante a atividade, ao relatarem que cortaram os pães, umedeceram algumas destas fatias e as guardaram em ambientes diferentes. Isso reitera a importância de os estudantes aprenderem a dominar as atividades investigativas, pois esse processo contribui para uma participação ativa na construção do próprio conhecimento.

Charlot (1996) defende que, na imbricação do eu, o Eu permanece imbricado na situação quando os estudantes evocam seus aprendizados. O Eu está no discurso, em situações diversas: lavando a louça, nadando, desenhando, calculando. Esse processo epistêmico está no domínio da atividade, no discurso sobre esse domínio em que o Eu é sujeito da ação.

Sendo assim, a partir dessa forma epistêmica os estudantes estabeleceram a relação com o aprender a dominar uma atividade de investigação científica sobre a proliferação do bolor. Carvalho et al. (2010) e Fireman e Brito (2018) oferecem explicações para compreensão sobre como as práticas investigativas contribuíram para o surgimento dessa relação.

Carvalho et al. (2010) entendem que uma atividade de ciências está fundamentada na ação dos estudantes. Nesse sentido, ao procurarem resolver questões propostas pelos professores, os estudantes devem levantar e testar hipóteses. Dentro dessa perspectiva, o ensino por investigação cria um ambiente de aprendizagem em que o discente precisa adquirir a habilidade de argumentar e, por meio dos dados obtidos, construir justificativas para agir diante da problemática proposta.

Fireman e Brito (2018) afirmam que nas atividades investigativas a tomada de consciência da ação sobre o objeto de estudo é um processo metacognitivo, pois o estudante ao pensar ou refletir sobre suas próprias ações constrói uma aprendizagem em que suas atuações e interações são centrais durante o desenvolvimento do processo. Ou seja, a aprendizagem não ocorre somente pelas explicações de conceitos apresentados pelo professor, mas mediante protagonismo.

Outro processo epistêmico com o aprender analisado foi a distanciação-regulação. Para Charlot (2000) na distanciação-regulação o aprender é entrar em formas relacionais e dominar 
seus comportamentos nas relações com os outros e consigo mesmo. Essa forma epistêmica envolve a reflexão, a afetividade e outros comportamentos, "[...] é o sujeito afetivo e relacional, definido por sentimentos e emoções em situação e em ato; [...] o sujeito como sistema de condutas relacionais, como conjunto de processos psíquicos [...]." (CHARLOT 2000, p. 70).

Esse processo epistêmico foi identificado a partir das respostas dadas às seguintes perguntas: você achou importante estudar sobre esse assunto? Por quê? Vale ressaltar que os estudantes A4, A6, A11, A14, A15 e A19 conseguiram desenvolver os processos epistêmicos da objetivação-denominação e imbricação do eu, porém não foi identificado o processo da distanciação-regulação em suas falas. Já os estudantes $A 8$ e A12, por seu turno, não desenvolveram nenhum dos três processos epistêmicos com o aprender e suas respostas podem ser observadas, a seguir.

Tia, tá tudo misturada na minha cabeça. Aí não sei dizer para a senhora (A8).

Não lembro. (A12).

As respostas obtidas nesse processo epistêmico com o aprender foram organizadas em duas constelações: a) os malefícios que os fungos causam à saúde; e b) os fungos que são prejudiciais e os que não causam danos à saúde. É importante ressaltar que uma mesma fala pode pertencer a constelações diferentes.

No Quadro 11, abaixo, são apresentadas as falas que formaram a constelação: os malefícios que os fungos causam à saúde.

Quadro 11 - Respostas dos estudantes relacionadas ao processo epistêmico da distanciação-regulação que originaram a constelação: os malefícios que os fungos causam à saúde.

\begin{tabular}{|c|l|}
\hline \multicolumn{2}{|c|}{ Os malefícios que os fungos causam à saúde } \\
\hline Locutor & $\begin{array}{l}\text { Sim. Tipo assim eu estava brincando. Aí a bola bateu em uma parede, eu } \\
\text { fui lá buscar e tinha fungos lá. Foi nesse mês mesmo. Tinha fungos lá. Aí } \\
\text { eu falei olha isso aqui eu aprendi lá na escola, os fungos. Melhor lavar a } \\
\text { bola pra não me contaminar }\end{array}$ \\
\hline A2 & $\begin{array}{l}\text { Quando eu for fazer alguma coisa, não deixar as coisas pegar o fungo. } \\
\text { Tem que comer logo. }\end{array}$ \\
\hline A3 & $\begin{array}{l}\text { Estudar sobre os fungos é uma coisa muito importante porque se a gente } \\
\text { vê um fungo e não reconhecer a gente pode acabar comendo e passando } \\
\text { muito mal e vai ter que ir para o hospital. }\end{array}$ \\
\hline A5 & $\begin{array}{l}\text { Que os fungos gostam mais do molhado e não pode comer mofo que faz } \\
\text { mal, dá dor de barriga, passa mal. }\end{array}$ \\
\hline A7 & $\begin{array}{l}\text { Porque quando eu ver em alguma coisa eu não como porque vai fazer } \\
\text { mal pra mim. }\end{array}$ \\
\hline
\end{tabular}




\begin{tabular}{|c|l|}
\hline A13 & $\begin{array}{l}\text { Quando a comida tá com mancha verde é porque tá estragada e se eu } \\
\text { comer vou passar mal. }\end{array}$ \\
\hline A16 & $\begin{array}{l}\text { Que não se deve cortar a parte que tá verde e comer a outra que tá limpa. } \\
\text { Porque se o fungo entra em uma parte, ele está em tudo. Se alguém na } \\
\text { minha casa fizer isso, vou dizer que não é pra comer porque vai passar } \\
\text { mal. Foi muito importante saber disso. }\end{array}$ \\
\hline
\end{tabular}

Fonte: Elaborado pelas autoras.

Dentro desse contexto, os estudantes $A 17, A 18, A 20$ e $A 21$ também se referiram aos malefícios que os fungos podem causar à saúde humana no caso de consumo de alimentos com mofo.

Nesta constelação, os estudantes atribuíram ao fungo o perigo que ele pode causar à saúde. A partir dela pode-se observar que uma relação epistêmica com o aprender foi estabelecida: a relação com o aprender a cuidar da saúde. Ou seja, os estudantes estabeleceram uma relação consigo mesmos, eles se veem em determinadas situações do cotidiano, como a fala de A1 demonstra, ou em situações que ainda podem acontecer, como explicaram A2, A3, A7, A13 e A16 sobre os riscos que o contato com certos fungos, mais especificamente o bolor ou mofo, representam ou podem representar, não somente à própria saúde, mas também à de outras pessoas, expressando cautela sobre essas circunstâncias. Acerca disso, Charlot (2005) argumenta que aprender é tornar-se capaz de regular essa relação encontrando a distância conveniente entre si e os outros, entre si e si mesmo.

Já na constelação "os fungos que são prejudiciais e os que não causam danos à saúde" apresentou as reflexões constituídas por um equilíbrio do pensamento científico. Além dos estudantes refletirem sobre os antibióticos originados por meio dos fungos e sobre os cogumelos que podem ser consumidos sem que representem perigo à saúde, as crianças também expressaram os prejuízos que o bolor e os cogumelos venenosos podem causar. Os trechos das entrevistas estão no Quadro 12, a seguir.

Quadro 12 - Respostas dos estudantes relacionadas ao processo epistêmico da distanciação-regulação que originaram a constelação: os fungos que são prejudiciais e os que não causam danos à saúde.

\begin{tabular}{|c|l|}
\hline \multicolumn{2}{|c|}{ Os fungos que são prejudiciais e os que não causam danos à saúde } \\
\hline Locutor & \multicolumn{1}{|c|}{ Falas transcritas } \\
\hline A9 & $\begin{array}{l}\text { Eles curaram as feridas nas guerras. Eles também podem ficar nos } \\
\text { alimentos deixando verdes com bolor e se eu comer tem risco de } \\
\text { morte. }\end{array}$ \\
\hline A10 & $\begin{array}{l}\text { Mais ou menos. Porque uma parte eu achei importante pra quando } \\
\text { a gente estiver em uma selva saber que o cogumelo pode ser } \\
\text { perigoso pra comer porque tem o venenoso e o saudável. Os fungos } \\
\text { são bons pra criar remédios como o antibiótico que faz bem pra } \\
\text { saúde. }\end{array}$ \\
\hline
\end{tabular}

Fonte: Elaborado pelas autoras. 
Ademais, através da análise desta constelação foi possível observar como A9 e A10 construíram uma relação consigo próprio em determinadas situações que poderiam ocorrer em seus respectivos cotidianos. A9 relata sobre os riscos oferecidos à sua própria saúde caso consuma alimentos estragados; A10, por sua vez, expressa a importância do conteúdo estudado para determinadas circunstâncias da vida, expressando as precauções adquiridas a partir do estudo sobre os fungos, tanto para seu próprio bem-estar quanto para o de outras pessoas.

Diante disso, Charlot (2000) explica que por meio da forma epistêmica da distanciaçãoregulação pode-se adquirir uma posição reflexiva e designar a relação. A partir da reflexão apresentada por A10, outra relação é estabelecida: a relação com a importância de aprender sobre o conteúdo fungos.

Acerca das reflexões realizadas pelas crianças que constituíram cada constelação e das relações estabelecidas a partir da aplicação da aula, na perspectiva do ensino por investigação, pode-se observar que, assim como defende Charlot (2005), aprender não diz respeito somente à aquisição de saberes ou de enunciados. Aprender está na apropriação de práticas, de formas relacionais e no confrontar-se com a questão do sentido da vida, do mundo e de si mesmo.

\section{Considerações finais}

A partir da análise das entrevistas, constatou-se que mais da metade dos estudantes desenvolveram os três processos epistêmicos propostos por Charlot, por meio dos quais foram estabelecidas cinco relações com o aprender durante o desenvolvimento da aula, quais sejam: a relação com o aprender na descrição de conceitos de um conteúdo intelectual; a relação com o aprender a denominar um conteúdo intelectual; a relação com o aprender a dominar uma atividade de investigação científica sobre os fungos; a relação com o aprender a cuidar da saúde; a relação com a importância de aprender sobre o conteúdo fungos.

Essas relações foram estabelecidas a partir dos seguintes processos que envolveram a sequência de ensino investigativa no estudo sobre os fungos: a colocação de uma problemática, as observações realizadas, os questionamentos, as discussões desenvolvidas em sala de aula, a comunicação e o registro dos resultados obtidos. Essas circunstâncias colaboraram para a construção do conhecimento e para tomada de consciência por parte dos discentes.

$\mathrm{Na}$ presente pesquisa, durante o desenvolvimento das análises, observou-se que os estudantes A4, A6, A11, A14, A15 e A19 desenvolveram os processos epistêmicos da objetivação-denominação e da imbricação do eu, mas não o da distanciação-regulação. Já os estudantes A8 e A12 não desenvolveram nenhum dos processos epistêmicos analisados e, por conseguinte, não estabeleceram relações com o aprender. Assim, a criação de novas possibilidades em sala de aula, como por exemplo, o trabalho em grupo para realização da atividade investigativa, poderia ter contribuído para mudança desse cenário.

Desse modo, cabe esclarecer alguns motivos que podem ter colaborado para o surgimento dessas situações: a elaboração da sequência de ensino investigativa aplicada nesta pesquisa pode ter deixado lacunas; limitações quanto ao desempenho da prática docente; as 
situações de fracasso escolar explicadas por Charlot (2000) e outros fatores que envolvem a vida escolar da criança e que necessitam de análises detalhadas para serem identificados.

Sobre isso, Charlot (2000) argumenta que não existe "fracasso escolar", mas situações de fracasso escolar, situações em que os estudantes não conseguem aprender. Segundo o autor, essas circunstâncias e esses estudantes devem ser analisados detalhadamente e não tratados como incógnitas. Frente a isso, emerge outro questionamento, que poderá ser discutido em pesquisas futuras: quais fatores impedem os estudantes de estabelecer relações com o aprender diante da perspectiva do ensino por investigação na disciplina de ciências?

\section{Referências}

AZEVEDO, M. C. P. S. Ensino por investigação: problematizando as atividades em sala de aula. In: CARVALHO, Ana Maria Pessoa (org.). Ensino de Ciências: unindo a pesquisa e a prática. São Paulo: Scipione, 2004.

ASTOLFI, J.; PETERFALVI, B.; VÉRIN, A. Como as crianças aprendem as Ciências. Lisboa: Instituto Piaget, 1998.

BAUER, M. W.; GASKELL, G. Pesquisa qualitativa com texto, imagem e som. 2. ed. Rio de Janeiro: Vozes, 2003.

BRASIL. Ministério da Educação. Base Nacional Comum Curricular (BNCC). Brasília: MEC. 2017. Disponível em:<http://basenacionalcomum.mec.gov.br/images/BNCC_20dez_site.pdf

> Acesso 05 jul. 2018.

BORGES, A. T. Novos rumos para o laboratório escolar de ciências. Caderno Brasileiro. Ensino de Física, v. 19, n. 3, p. 291-313, dez. 2002.

CANTO, E. L. Ciências Naturais: aprendendo com o cotidiano. 4. ed. São Paulo: Moderna, 2012.

CARVALHO, A. M. P. et al. Ciências no Ensino Fundamental: o conhecimento físico. São Paulo: Scipione, 2010.

CARVALHO, A. M. P. O ensino de Ciências e a proposição de sequências de ensino investigativas. In: CARVALHO, A. M. P. (Org.). Ensino de ciências por investigação: condições para implementação em sala de aula. São Paulo: Cengage Learning, p. 01-20, 2013.

CARVALHO, A. F. N. As relações com o aprender: sentidos atribuídos pelos alunos à escola e ao ensino de ciências por investigação. Dissertação (Mestrado em Educação) - Universidade Federal do Paraná, 2017.

CHARLOT, B. Relação com o saber e com a escola entre estudantes de periferia. Cadernos de pesquisa, n. 97, p. 47-63, maio 1996.

CHARLOT, B. Da relação com o saber: elementos para uma teoria. Porto Alegre: Artmed, 2000.

CHARLOT, B. Relação com o saber, formação de professores e globalização: questões para a educação hoje. Porto Alegre: Artmed, 2005. 
CHARLOT, B. A relação com o saber nos meios populares: uma investigação nos liceus profissionais de subúrbio. Trad. Cataria Matos. Porto: Livpsic, 2009.

CHARLOT, B. Da relação com o saber ás práticas educativas. 1.ed. São Paulo: Cortez, 2013.

FIREMAN, E. C.; BRITO, L. O. Ensino de ciências por investigação: uma proposta didática "para além" de conteúdos conceituais. Experiências em Ensino de Ciências, v. 13, n. 5, 2018.

FLICK, W. Introdução à pesquisa qualitativa. 3. ed. Porto Alegre: Artmed, 2009.

GIL PÉREZ, D.; VALDÉS CASTRO, P. Lá orientación de las prácticas de laboratorio como investigación: un ejemplo ilustrativo. Enseñanza, v. 14, n. 2, p. 155-163, 1996.

GOWDAK, M.; MARTINS, E. Ciências novo pensar. São Paulo: FTD, 2009.

LAVILLE, C.; DIONNE, J. A construção do saber: manual de metodologia da pesquisa em ciências humanas. Porto Alegre: Artmed, 1999.

LEWIN,K. Teoria de campo em ciência social. São Paulo: Pioneira, 1965.

MINAYO, M. C. S. Pesquisa Social: teoria, método e criatividade. 18. ed. Petrópolis: Vozes, 2001.

MOTTA, C. Aprender juntos ciências, 4ํano: ensino fundamental. 5. ed. São Paulo: Edições SM, 2016.

OLIVEIRA, C. M. A. O que se fala e escreve nas aulas de ciências? In: CARVALHO, A. M. P. (Org). Ensino de ciências por investigação: condições para implementação em sala de aula. São Paulo: Cengage Learning, 2013.

PEREIRA, J. E. D. A pesquisa dos educadores como estratégia para construção de modelos críticos de formação docente. In: PEREIRA, J. E. D.; ZEICHNER, K. M. (org.). A pesquisa na formação e no trabalho docente. 2. ed. Belo Horizonte: Autêntica editora, 2011.

POZO, J. I.; CRESPO, M. Á. G. A aprendizagem e o ensino de ciências: do conhecimento cotidiano ao conhecimento científico. 5. ed. Artmed: Porto Alegre, 2009.

RABONI, P. C. A.; CARVALHO, A. M. P. Solução de problemas experimentais em aulas de ciências nas séries iniciais e o uso da linguagem cotidiana na construção do conhecimento científico. In: Atas do IX Encontro Nacional de Pesquisa em Educação em Ciências, 9, 2013, São Paulo. Anais...Águas de Lindóia, SP, 2013.

RODRIGUES, A. S.; TEIXEIRA, A. M. F. Teatro científico e mobilização: aproximações a partir de um balanço bibliográfico e a teoria da relação com o saber. Ensino de Ciências e Tecnologia em Revista, v. 9, p. 49-60, 2018.

SASSERON, L. H. Interações discursivas e investigação em sala de aula: o papel do professor. In: CARVALHO, A. M. P. (Org.). Ensino de ciências por investigação: condições para implementação em sala de aula. São Paulo: Cengage Learning, 2013.

SASSERON, L. H. Alfabetização científica, ensino por investigação e argumentação: relações entre ciências da natureza e escola. Revista Ensaio, Belo Horizonte, v. 17, p. 49-67, 2015.

SERRA, H. (org). Ensino de ciências e educação para a saúde: uma proposta de abordagem. Dourados - MS: Ed. UFGD, p. 151, 2013. 
SILVA, S. E. R. da. Decomposição dos alimentos: ação dos microrganismos. Monografia (PósGraduação em Especialização em Ensino de Ciências, Modalidade de Ensino a Distância) Universidade Tecnológica Federal do Paraná, 2012.

TRIVIÑOS, A. N. S. Introdução à pesquisa em ciências sociais: a pesquisa qualitativa em educação. São Paulo: Atlas, 1987.

ZANON, D. A. V.; FREITAS, D. A aula de ciências nas séries iniciais do ensino fundamental: ações que favorecem a sua aprendizagem. Ciências \& Cognição, v.10, p. 93-103, 2007.

ZÔMPERO, A. F.; LABURÚ, C. E. Atividades investigativas no ensino de ciências: aspectos históricos e diferentes abordagens. Ensaio Pesquisa em Educação em Ciências (Belo Horizonte), v. 13, n. 3, p.67-80, 2011. 